\title{
Review
}

Journal of Innate

Immunity

\section{Current Concepts and Controversies in Innate Immunity of Cystic Fibrosis Lung Disease}

\author{
Anjali Ralhan ${ }^{a} \quad J_{\text {Julie Laval }}{ }^{a} \quad$ Felipe Lelis $^{a} \quad$ Marlene Ballbach $^{a} \quad$ Charlotte Grund $^{a}$ \\ Andreas Hector ${ }^{a}$ Dominik Hartl ${ }^{a, b}$

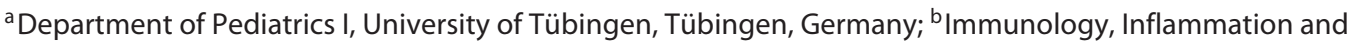 \\ Infectious Diseases (I3) Discovery and Translational Area, Roche Pharma Research and Early Development (pRED), \\ Roche Innovation Center Basel, Basel, Switzerland
}

\section{Key Words}

Cystic fibrosis - Lung disease $\cdot$ Host defense - Immune response $\cdot$ Neutrophils . Pattern recognition receptors . Toll-like receptor

\begin{abstract}
Cystic fibrosis (CF) lung disease is characterized by chronic infection and inflammation. The inflammatory response in $\mathrm{CF}$ is dominated by the activation of the innate immune system. Bacteria and fungi represent the key pathogens chronically colonizing the CF airways. In response, innate immune pattern recognition receptors, expressed by airway epithelial and myeloid cells, sense the microbial threat and release chemoattractants to recruit large numbers of neutrophils into CF airways. However, neutrophils fail to efficiently clear the invading pathogens, but instead release harmful proteases and oxidants and finally cause tissue injury. Here, we summarize and discuss current concepts and controversies in the field of innate immunity in CF lung disease, facing the ongoing questions of whether inflammation is good or bad in CF and how innate immune mechanisms could be harnessed therapeutically.

(c) 2016 S. Karger AG, Basel
\end{abstract}

\section{CF Lung Disease}

Cystic fibrosis (CF) lung disease, the most common inherited lethal disease in Caucasians [1], is characterized by an early [2], nonresolving [3] and harmful [3, 4] activation of the innate immune system. CF is caused by mutations in the CF transmembrane conductance regulator (CFTR) gene, mainly expressed at the apical membrane of epithelial cells [5]. However, besides CFTR, other genes ('modifier genes') also appear to play a significant role in modulating lung disease severity and immune response [6-9], particularly genetic variants of transforming growth factor $\beta_{1}$ (TGF- $\left.\beta_{1}\right)$ [10-12], mannose-binding lectin (MBL2) [13] and interferon-related developmental regulator 1 (IFRD1) $[14,15]$. Exome sequencing has revealed that the variants in dynactin protein, DCTN4, are linked with the chronic infections in CF [16]. A more recent meta-analysis [17] has identified 5 loci: MUC4/ MUC20, SLC9A3, HLA Class II and AGTR2/SLC6A14 to be associated with the lung function in CF. Labenski et al. [18] have reported 2 cytokine receptor genes, INFGR1 and $I L 1 B$, and a transcription factor, STAT3, which is associated with the basic CFTR defect as candidate modi-

\section{KARGER}

E-Mail karger@karger.com

www.karger.com/jin
(C) 2016 S. Karger AG, Basel

$1662-811 \mathrm{X} / 16 / 0086-0531 \$ 39.50 / 0$
Dr. A. Ralhan or Prof. Dr. D. Hartl

Department of Pediatrics I, University of Tübingen Hoppe-Seyler-Strasse 1

DE-72076 Tübingen (Germany)

E-Mail Anjali.Ralhan@med.uni-tuebingen.de or Dominik.hartl@ med.uni-tuebingen.de 
fier genes in a study comparing F508del homozygous CF patient subsets. Some lesser-known genetic variations linked to CF lung disease are EDNRA [19], IL-8 [20] and SERPINA1 [9].

Studies from regions with CF newborn screening indicate that the innate immune system, as reflected prototypically by neutrophil products present in CF airway fluids, is operative in infants with CF and predicts the later outcome of irreversible pulmonary disease [2]. Based on these and other studies, innate immune cells have come into the focus of understanding and treating CF lung disease [3]. Whilst there are several studies supporting the notion that unopposed neutrophil products, such as extracellular elastase, are detrimental for tissue integrity and innate immune cell receptors $[3,21]$ and can be used as noninvasive biomarkers for CF airway inflammation $[22,23]$, therapeutic approaches to dampen excessive neutrophilic inflammation in CF lung disease have remained largely unsuccessful [24]. Neutralizing neutrophil elastase (NE) by using antiproteases showed some effects in preclinical and clinical studies; however, the benefits for lung function are so far not convincing [25]. Interfering with neutrophil recruitment through CXCR2 antagonists was safe and showed anti-inflammatory potential, yet no beneficial effects on lung function were found [26]. As CF airways are chronically colonized with bacteria and fungi [27], completely abrogating neutrophil recruitment into the lung bears the inherent risk of unleashing bacterial and fungal infections. Collectively, innate immune pathways are activated early in CF and seem to cause more harm than good within the pulmonary microenvironment; however, the therapeutic implications of these insights remain a matter of debate. To dissect the innate immune response in CF and develop future pharmacotherapeutic strategies, we have composed this review, embedded in a thematic CF series in the Journal of Innate Immunity.

\section{Current Controversies in Innate Immunity of CF Lung Disease}

Innate immunity comprises both cellular and humoral factors. Here, we focus on the cellular components of innate immunity and their pathogenic, diagnostic and/or potentially therapeutic role in CF lung disease. However, before considering innate immune cells as pharmacotherapeutic targets, one must understand their activation and effector functionalities. Therefore, we start with summarizing and discussing the mechanisms by which innate immune cells sense and are activated by CF pathogens. Based on this, we focus on the role of neutrophils, probably the key type of innate immune cell in CF lung disease, including their distinct innate immune receptor profiles and phenotypes in the proinflammatory CF airway microenvironment. Overall, our review should stir a discussion of the following controversies in the field:

- Is inflammation good or bad in CF lung disease? The correlation between neutrophil activation and irreversible lung tissue remodeling (bronchiectasis) [2] suggests a harmful role, but without functional neutrophils (as exemplified in patients with the primary immunodeficiency chronic granulomatous disease), we cannot efficiently defend against bacteria and fungi. Consequently, dampening neutrophil activation would be reasonable, while completely abrogating neutrophil influx or function might be dangerous.

- How does harmful proinflammatory neutrophil activation in CF get dampened? Harmful unopposed neutrophil functions, such as unopposed protease release and neutrophil extracellular trap (NET) formation should be controlled, but how? Antiproteases show limited success so far, but studies are ongoing. NET formation still represents a controversial area [28]. On the one hand, NETs can entrap pathogens and may therefore act beneficially. On the other hand, abundant NETs, as found in CF airways, can obstruct the airway lumen and correlate with decreased lung function in CF patients [29]. Recombinant DNase (Dornase alfa) is clinically effective in CF patients by cleaving DNA strands and facilitating airway mucus clearance [30]. A recent study suggested that the majority of extracellular DNA in CF airways is derived from NETs [31]. Thus, the clinical effectiveness of recombinant DNase might support the concept that the prevalence of NETs causes more harm than good in CF lung disease. However, DNases cleave extracellular DNA and do not prevent de novo NET generation or release. Approaches how to target NET generation may involve interfering with reactive oxygen species (ROS) or MAPK, which have been found important for NET formation $[32,33]$. Studies comparing the effect of inhibiting intracellular NET generation versus cleaving free extracellular DNA strands would shed more light on the kinetics and dynamics of NET-pathogen interactions in lung disease and beyond. Alternatively, specific neutrophil phenotypes, such as olfactomedin-4or CD177-expressing neutrophil subsets, could be targeted [28]. Their functional role and CF disease relevance remains to be defined. 
- When should inflammation be targeted? At first glance, the earlier, the better, in order to prevent inflammation-associated tissue damage and avoid irreversible pulmonary tissue remodeling as soon as possible in the course of disease. On the other hand, neutrophils could be essential in early host-pathogen interactions by restricting airway pathogen colonization in the first years of life, when the airways are intensively exposed to environmental microbes and vaccinations are performed. Further investigations into $\mathrm{CF}$ lung disease are required to define the time windows when inflammation could be targeted safely without significantly impairing the protective innate immune defenses.

\section{Innate Immune Activation in CF Lung Disease}

Sensitive microbial detection mechanisms as well as tailored immune responses are required to efficiently protect the host from pathogens. Simultaneously, inflammation has to be tightly controlled and limited to avoid overshooting immune responses and collateral tissue injury. In 1989, Janeway [34] proposed the pattern recognition theory, stating that the microbial presence is sensed by the host innate immune system through the detection of distinct molecular structures called pathogen-associated molecular patterns (PAMPs) that are expressed by the pathogen but are absent in the host. To sense the presence of microorganism, the cells of the immune system possess germline-encoded pattern recognition receptors (PRRs) with 4 different families having been currently identified. These families include transmembrane proteins such as Toll-like receptors (TLRs) and C-type lectin receptors (CLRs) as well as cytoplasmic proteins such as the retinoic acid-inducible gene (RIG)-I-like receptors (RLRs) and NOD-like receptors (NLRs). Apart from PAMPs, PRRs also recognize host-derived patterns/molecules, termed damage- or danger-associated molecular patterns (DAMPs).

CF lung disease is mainly characterized by bacterial and fungal colonization and infection. Therefore, in the sections below, we will focus on these 2 microbial entities and the corresponding innate immune responses.

\section{Bacterial Recognition: TLRs}

The main bacteria commonly identified in CF lungs in early disease/infancy are Staphylococcus aureus and Haemophilus influenzae, followed in adolescence and adulthood by the major CF pathogen Pseudomonas ae- ruginosa. However, beyond these 'classical' CF bacteria, microbiome studies indicate that a much broader variety of bacterial species, including anaerobes, colonize CF airways [35-37]. TLRs are the main innate immune receptors (PRRs) to sense bacteria. Ten and 12 TLRs have been identified in humans and mice, respectively, and TLR19 are conserved in both species [38]. The PRRs responsible for the recognition of $P$. aeruginosa in CF lung disease are TLRs, Asialo-GM1 receptors [39] and the NLRC4/IPAF inflammasome [40]. TLR2, TLR4, TLR5 and/or TLR9 have been reported to sense $P$. aeruginosa [41]. The bacteria-derived ligands known to bind TLR2 are lipoproteins, components of the extracellular capsule and secreted toxin, ExoS, with C-terminal-specific interaction [42-44]. Reports have shown a role for TLR2 in the recognition of mannuronic acid polymer, a major component of the alginate capsule and slime GLP, produced by mucoid and nonmucoid strains of $P$. aeruginosa $[45,46]$. Lipopolysaccharide (LPS) is mainly sensed through TLR4 and, after recognition, the TLR4/LPS complex is rapidly endocytosed and trafficked for lysosomal degradation in order to terminate further inflammatory cascades [47]. The lipid A component of LPS ligates TLR4, inducing a potent immune response [48], with the hexacyclated form being a strong activator of TLR4-mediated signaling in humans [49]. Hexacylated lipid A is often produced by bacterial strains adapted to the chronic CF microenvironment [50, 51], leading to escape from the host antimicrobial peptides and increased recognition by human TLR4. In contrast to this structural peculiarity, a recent study by Di Lorenzo et al. [52] sheds new light on the activation mechanism of TLR4/MD2 complex by penta-acylated lipid A produced by the CF isolates of Burkholderia cenocepacia. TLR5 specifically binds to flagellin, a primary constituent of flagella important for microbial motility [53]. However, the correlation between bacterial motility and immune evasion by $P$. aeruginosa remains controversial [54]. An in vivo study highlighted the proinflammatory role of flagellin-mediated TLR5 activation [55]. Descamps et al. [56] reported that TLR5, rather than TLR4, is essential for bacterial phagocytosis and killing by murine alveolar macrophages (AMs) in vitro and in vivo. The authors also demonstrated that nonflagellated $P$. aeruginosa or mutants defective in TLR5 activation are resistant to AM clearing, which is dependent on TLR5 signaling and IL$1 \beta$ production. The intracellular function of TLR9 is characterized by detection of unmethylated CpG motifs in bacterial DNA $[57,58]$. Synergistic effects of TLR2, TLR6 and TLR9 have been reported using in vivo studies 
[59]. Further studies report a resistant phenotype of TLR9 $^{-1-}$ mice to $P$. aeruginosa infection compared to wild-type mice [60]. These unexpected findings are attributed to increased airways cytokine production leading to effective bacterial clearance in the lungs of the TLR9 $^{-1-}$ mice.

\section{The NLRC4 and NLRP3 Inflammasomes}

NLRs are cytosolic proteins that respond to a variety of ligands, from bacterial and viral components to particulate matter and crystals. The mammalian NLR family comprises $>20$ members, containing a C-terminal leucine-rich repeat domain, a central nucleotide-binding $\mathrm{NACHT}$ domain and an $\mathrm{N}$-terminal protein-protein interaction domain composed of a caspase activation and recruitment domain (CARD) or Pyrin domain [61-63]. The transmembrane secretion systems of intracellular pathogens or bacteria serve as cytosolic microbe-associated molecular patterns (MAMPs) that may interact with NLRs [64-66]. Regarding human pulmonary pathogens, NLRC4 and NLRP3 are the 2 most widely studied NLRs that orchestrate immune responses [67-69]. In addition to TLR5, bacterial flagellin is sensed by NLRC4 [70, 71]. Sutterwala et al. [40] have further described that NLRC4 triggers the activation of the inflammasome upon infection with $P$. aeruginosa, resulting in macrophage cell death and the secretion of the proinflammatory cytokines, IL-1 $\beta$ and IL-18. This activation cascade was shown to be IPAF-dependent, but flagellin-independent. Moreover, in vivo studies revealed an increased susceptibility of NLRC4-deficient mice against $P$. aeruginosa infection [72]. In addition to Pseudomonas, other Gramnegative bacteria, such as Salmonella, Legionella and Shigella, have also been found to activate the NLRC4 inflammasome [73-75]. In a recent study, the role of NLRP3 inflammasome activation in the CF lung has been described in association with elevated levels of ceramide [76]. The authors demonstrated an upregulation and recruitment of the adapter protein apoptosis-associated speck-like protein (ASC) and caspase-1 in the lungs of CF mice. The activation of NLRP3 is characterized by a canonical two-step deubiquitination mechanism that is initiated by priming through TLR signaling (e.g. TLR4), inducing NF- $\kappa \mathrm{B}$-dependent NLRP3 protein synthesis, followed by a second signal leading to full NLRP3 inflammasome assembly [77]. In CF airway epithelial cells, $P$. aeruginosa infection has been shown to trigger mitochondrial dysfunction and enhance mitochondrial $\mathrm{Ca}^{2+}$ uptake, leading to NLRP3 inflammasome activation [78, 79].

\section{Fungal Recognition}

With constant inhalation of fungal spores, the human airway immune system has evolved a plethora of finetuned defense mechanisms for effective fungal clearance, involving, mainly, AM, neutrophils and antimicrobial peptides [80-85]. With ageing and more intensified antibiotic treatments, prevalence rates of fungal colonization increase in CF lung disease, traditionally known to be mainly colonized by a bacterial community [86-88]. The reported emerging rate of filamentous fungal species, such as Aspergillus fumigatus, in CF, is found to be most frequent; however, other important filamentous fungi including Scedosporium sp. and Exophiala dermatiditis have also been identified $[89,90]$. The sensitization of CF patients to the airway microenvironment presents a wide range of unresolved questions. However, previous reports have proposed a crucial role for dendritic cells and Th2-associated chemokines, like CCL17 [91]. Phagocytic cells play an essential role in protection against the fungal infections, and abrogation of these cells leads to increase susceptibility towards pathogens [92]. The receptors involved in these processes include secreted factors such as pentraxin-3 (PTX3), C-type lectins, complement system and membrane PRRs such as TLRs [93]. Previous reports have shown that A. fumigatus conidia are recognized by TLRs $[94,95]$ and $\beta$-glucan receptor dectin-1 on dendritic cells, AM and lung epithelial cells [96, 97]. TLRs, in particular TLR2 [98, 99], TLR4 [100, 101] or an interplay between TLR2, 4 and 9 via an MyD88dependent pathway [96], are described as playing an important role in the host immune response to A. fumigatus. The endocytic PRR dectin- 1 is crucial in the recognition and internalization of specific morphotypes of $A$. fumigatus in AM $[102,103]$, and a novel mechanism of dectin-1 induction in human bronchial epithelial cells and its consequences for innate immune responses against $A$. fumigatus have been described by Sun et al. [97]. Secreted receptor pentraxin PTX3 also plays an important role in the clearance of fungal burden in vivo after A. fumigatus pulmonary infection. PTX3 levels in a CF patient's respiratory secretions and sputum samples were found to have decreased [104]; this could be one of the explanations for recurrent lung infections in $\mathrm{CF}$ lungs. Another study showed that a serum opsonin, $\mathrm{H}$ ficolin, modulates host immune response by binding to A. fumigatus [105]. The authors further showed that following pathogen recognition, there is an enhanced activation of the lectin complement pathway and fungal association with lung epithelial cells. 


\section{Innate Immune Cells}

Airway epithelial cells form the first line of defense against microbial infections and serve as a central player in the mucociliary clearance of the lung. The key innate immune functions of the epithelium include (1) secretion of a variety of antimicrobial substances, (2) release of chemokines, cytokines and growth factors that mediate leukocyte recruitment, (3) modulation of adaptive immunity and (4) tissue repair and remodeling [3, 106, 107]. Direct interaction between the CFTR protein and pathogens has been previously suggested, where CFTR serves as a receptor for Salmonella typhi [108] and $P$. aeruginosa $[109,110]$ when expressed on intestinal or airway epithelial cells, respectively. Moreover, A. fumigatus spores are readily ingested by airway epithelial cells and the uptake and killing of conidia are both impaired in epithelial cells lacking CFTR [111]. The bronchial epithelium has been previously shown to modulate its sensitivity towards microbial recognition by regulating receptor expression levels [112]. Upon pathogen recognition by specific PRRs, the activation of intracellular signaling cascades initiates proinflammatory and antimicrobial responses. Bacterial infection in CF can exacerbate lung inflammation by exaggerating proinflammatory gene expression via TLR activation in airway epithelial cells [43]. In vitro as well as in vivo studies have shown that excessive cytokine release upon $P$. aeruginosa exposure to CF airway epithelial cells is mainly mediated by TLR5/flagellin or TLR4/LPS interactions $[113,114]$. In particular, intracellular TLR4 trafficking seems to be dysregulated and attenuated in human CF airway epithelial cells compared to non-CF cells [115-117]. Hyperresponsiveness of primary airway epithelial cells to LPS, despite expressing normal levels of TLR4, has been attributed to the reduced surface expression of coreceptor CD14 and lower levels of the costimulatory molecule MD2 [118]. Conflicting studies have been reported regarding the localization of TLR5 on airway epithelial cells, with apical dominance on human and murine cells [119-122] and basolateral expression on polarized human nasal and bronchial epithelium [123-125]. Specific cell source, modulation of culture conditions and/or specific stimuli might explain these discrepancies. A strong synergism between TLR2/PGN- and TLR4/LPSmediated IL-8 production and IL17A was found in human bronchial epithelial cell lines [126]. Recently, genotyping of TLR polymorphisms revealed that CF airway epithelial cells are homozygous for TLR1 SNP 1602S and possess a diminished innate immune response towards Mycobacterium abscessus infection. [127]. In a separate study, TLR SNPs were associated with CF lung function decline [128]. A recent study [129] demonstrated that $S$. aureus filtrates inhibit $P$. aeruginosa filtrate-mediated IL-8 production.

The CF airways are characterized by a neutrophil-rich environment. Neutrophils have been mainly implicated in controlling bacterial and fungal infections, but can also lead to airway damage upon activation through the release of enzymes (proteases) and oxidants [28]. Neutrophils are the first cell type recruited to the CF airway compartment. The recruitment of blood neutrophils into the airway compartment is mainly regulated through chemokines, such as IL-8, and lipid-mediators, such as $\mathrm{LTB}_{4}$. The efficient antibacterial function of neutrophils in the $\mathrm{CF}$ airway micromilieu is impeded due to several mechanisms, such as proteolytic damage of airway neutrophils, neutrophil cell death and bacterial/fungal biofilm formation that prevents phagocytosis [3]. At the site of infection, neutrophils sense PAMPs or DAMPs via PRRs. Expression and functionality of TLRs in neutrophils have been studied in the context of CF lung disease. Collectively, TLR2, TLR4 and TLR5 are suggested to be most essential for neutrophil- $P$. aeruginosa interactions. CF airway neutrophils express remarkably high levels of TLR5, which correlates with lung function in CF patients $[130,131]$. In a separate study, TLR surface expression was investigated on circulating and induced sputum neutrophils in CF patients. Compared to healthy controls, decreased expression of TLR 2 was detected on circulating neutrophils in CF patients [132]. Furthermore, an inverse relationship between TNF- $\alpha$ serum levels and TLR 2 surface expression on circulating neutrophils has been described [130]. DAMPs such as proline-glycine-proline and high-mobility group box protein-1 (HMGB1) have been implicated in CF lung disease. A high concentration of these mediators is found in CF airways and they serve as neutrophil chemoattractants to drive lung inflammation [133]. S100A12, a member of the S100/calgranulin family and a neutrophil-derived DAMP, was found in abundance in $\mathrm{CF}$ airway fluids leading to activation of downstream metabolic and stress pathways following neutrophil entry into CF airways [134].

\section{Novel Therapeutic Concepts}

Despite a plethora of proinflammatory innate immune pathways having been studied and determined as playing a significant role in CF lung disease, therapeutic exploitation of these pathomechanisms remains scarce. For a broader and more in-depth discussion of this aspect, we 


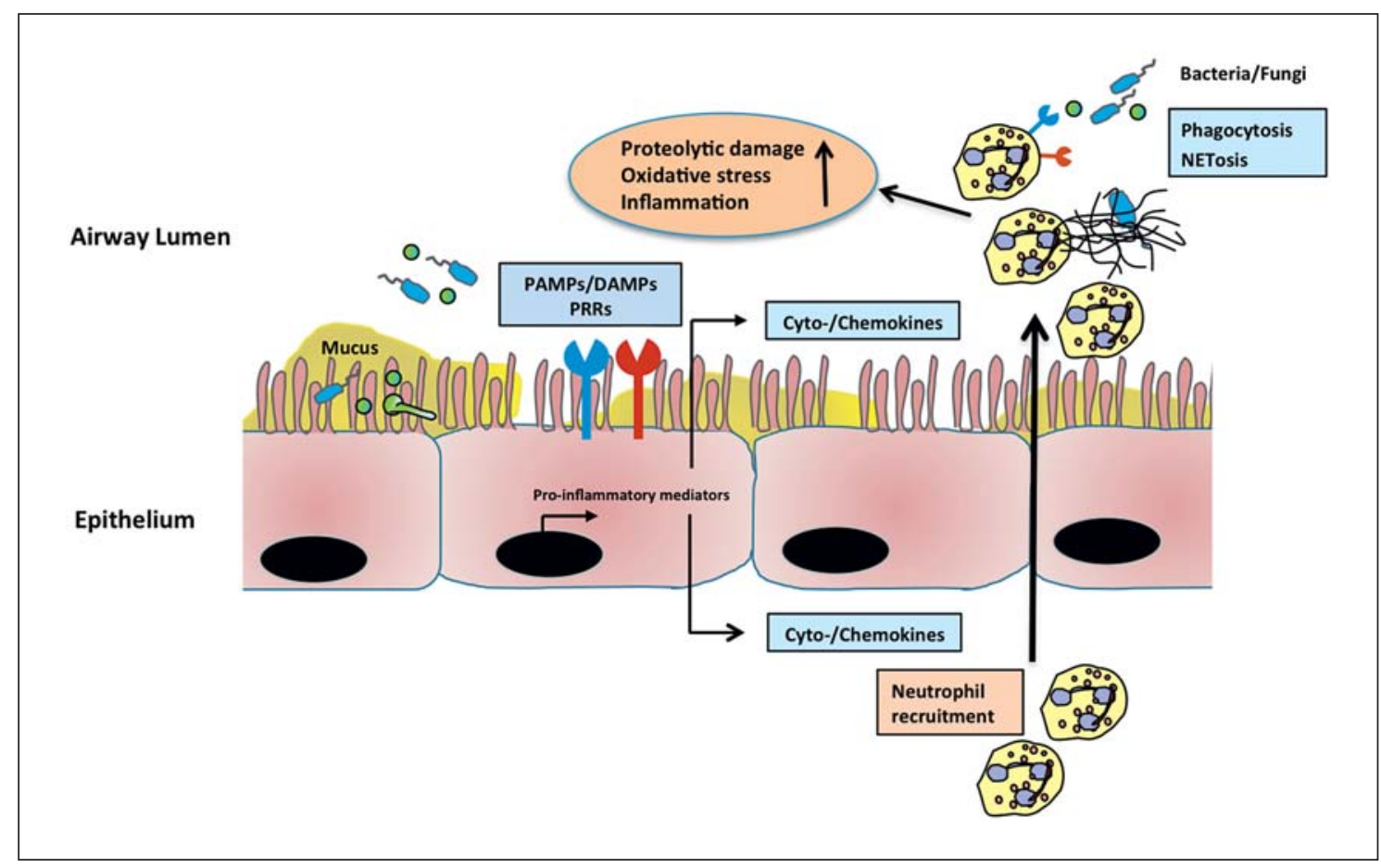

Fig. 1. Innate immune activation in CF airways. Due to continuous production of cytokines and chemokines, especially IL-8, neutrophils are recruited into the CF airways. Bacterial and fungal PAMPs and host-derived DAMPs further activate downstream signaling pathways through the activation of PRRs, and lead to enhanced cytokine and chemokine production. Infiltrated neutrophils release proteases and oxidants, resulting in perpetuated inflammation and tissue injury.

refer to thematic review articles [24, 135]. Ibuprofen represents a clinically available anti-inflammatory drug that has been shown to slow lung function decline in pediatric/adolescent CF lung disease [136-139], but its broad clinical usage outside the USA is restricted by drug-monitoring requirements. Correlations between lung function and inflammatory markers in CF airway fluids (neutrophil counts, IL- 8 and NE) have been demonstrated in multicenter CF patient cohorts [22], suggesting that targeting neutrophil-related products may be beneficial in $\mathrm{CF}$ lung disease. However, clinical studies aiming to neutralize free NE activity in CF airways by the delivery of antiproteases, such as $\alpha-1$ antitrypsin, showed modulated airway inflammation but failed to show convincing effects on lung function [25]. In contrast, the use of the oral antioxidant $\mathrm{N}$-acetylcysteine, as a strategy to rebalance antioxidant deficiencies in CF, shows beneficial effects on lung function, but has no effect on neutrophilic inflammation [140]. Future studies are required to reconcile these findings and to further assess the therapeutic potential of antiprotease or antioxidant approaches in CF lung disease $[24,141]$. The antibiotic azithromycin is known to have anti-inflammatory effects. A clinical trial [142] showed that azithromycin treatment reduced circulating neutrophil counts and systemic blood biomarkers, including C-reactive protein, serum amyloid A and calprotectin, and was correlated with the improvement in lung function and weight gain. Other anti-inflammatory therapeutic approaches include sildenafil (phosphodiesterase inhibitor) [143], CXCR2 inhibition [26] and others lessadvanced ones that are not discussed here. Collectively, therapeutic interventions to dampen inflammation in CF remain an appealing yet challenging approach.

\section{Conclusions and Outlook}

There is broad consensus about the concept that the innate immune system is activated early and strongly in CF lung disease, leading to the continuous recruitment of neutrophils into CF airways [3]. These neutrophils release proteases that cause harm to the host by degradation 
of the pulmonary tissue and the immune receptors (fig. 1). However, controversy exists as to whether the targeting of innate immune pathways, by neutrophil recruitment and/or activation, represents a promising strategy in $\mathrm{CF}$ lung disease. On the one hand, there are clear relationships between neutrophil products, prototypical NE and decreased lung function [22] as well as bronchiectasis [2]. On the other hand, targeting excessive proteolytic activities in CF has clinically not been successful so far. Interfering with neutrophil recruitment through CXCR2 inhibition represents a causative anti-inflammatory approach [26], but has also not shown any clinical benefits for lung function. Novel strategies to dampen innate immunity in $\mathrm{CF}$ in the future could involve anti-inflammatory proresolution lipid mediator pathways, such as resolvins [144], and the endocannabinoid system [145]. However, most of these pathways have mainly been assessed in acute lung inflammation models and not in chronic CF lung disease. Both preclinical and clinical studies are warranted to evaluate these and other anti-inflammatory mechanisms in the context of CF lung disease.

\section{Acknowledgements}

This work was supported by the German Research Foundation (DFG, SFB/CRC685 at Tübingen to D.H.) and European Respiratory Society (ERS RESPIRE 2 fellowship to J.L.). We thank Dr. Anurag Singh for kind assistance in designing the illustration.

\section{Disclosure Statement}

The authors have declared that no conflict of interests exists.

\section{References}

1 Mall MA, Hartl D: CFTR: Cystic fibrosis and beyond. Eur Respir J 2014;44:1042-1054.

-2 Sly P, Gangell C, Chen L, Ware R, Ranganathan S, Mott LS, et al: Risk factors for bronchiectasis in children with cystic fibrosis. N Engl J Med 2013;368:1963-1970.

>3 Hartl D, Gaggar A, Bruscia E, Hector A, Mar$\cos \mathrm{V}$, Jung A, et al: Innate immunity in cystic fibrosis lung disease. J Cyst Fibros 2012;11: 363-382.

-4 Rieber N, Hector A, Kuijpers T, Roos D, Hartl D: Current concepts of hyperinflammation in chronic granulomatous disease. Clin Dev Immunol 2012;2012:252460.

5 Choi JY, Muallem D, Kiselyov K, Lee MG, Thomas PJ, Muallem S: Aberrant CFTR-dependent $\mathrm{HCO} 3$ - transport in mutations associated with cystic fibrosis. Nature 2001;410: 94-97.

6 Drumm ML, Konstan MW, Schluchter MD, Handler A, Pace R, Zou F, et al: Genetic modifiers of lung disease in cystic fibrosis. N Engl J Med 2005;353:1443-1453.

7 Collaco JM, Cutting GR: Update on gene modifiers in cystic fibrosis. Curr Opin Pulm Med 2008;14:559-566.

8 Cutting GR: Modifier genes in Mendelian disorders: the example of cystic fibrosis. Ann NY Acad Sci 2010;1214:57-69.

9 Guillot L, Beucher J, Tabary O, Le Rouzic P, Clement A, Corvol H: Lung disease modifier genes in cystic fibrosis. Int J Biochem Cell Biol 2014;52:83-93.

10 Arkwright P, Laurie S, Super M, Pravica V, Schwarz M, Webb A, et al: TGF- $\beta 1$ genotype and accelerated decline in lung function of patients with cystic fibrosis. Thorax 2000;55: 459-462.
11 Brazova J, Sismova K, Vavrova V, Bartosova J, Macek M, Lauschman H, et al: Polymorphisms of TGF-betal in cystic fibrosis patients. Clin Immunol 2006;121:350-357.

12 Knowles MR, Drumm M: The influence of genetics on cystic fibrosis phenotypes. Cold Spring Harb Perspect Med 2012;2:1-13.

13 Garred P, Pressler T, Madsen HO, Frederiksen B, Svejgaard A, Høiby N, et al: Association of mannose-binding lectin gene heterogeneity with severity of lung disease and survival in cystic fibrosis. J Clin Invest 1999;104:431437.

14 Gu Y, Harley ITW, Henderson LB, Aronow BJ, Huber L a, Harley JB, et al: IFRD1 polymorphisms in cystic fibrosis with potential link to altered neutrophil function. Nature 2009;458:1039-1042.

15 Hector A, Kormann M, Kammermeier J, Burdi S, Marcos V, Rieber N, et al: Expression and regulation of interferon-related development regulator-1 in cystic fibrosis neutrophils. Am J Respir Cell Mol Biol 2013;48:71-77.

16 Emond MJ, Louie T, Emerson J, Zhao W, Mathias RA, Knowles MR, et al: Exome sequencing of extreme phenotypes identifies DCTN4 as a modifier of chronic Pseudomonas aeruginosa infection in cystic fibrosis. Nat Genet 2012;44:886-889.

17 Corvol H, Blackman SM, Boëlle P-Y, Gallins PJ, Pace RG, Stonebraker JR, et al: Genomewide association meta-analysis identifies five modifier loci of lung disease severity in cystic fibrosis. Nat Commun 2015;6:8382.
18 Labenski H, Hedtfeld S, Becker T, Tümmler $B$, Stanke F: Initial interrogation, confirmation and fine mapping of modifying genes: STAT3, IL1B and IFNGR1 determine cystic fibrosis disease manifestation. Eur J Hum Genet 2011;19:1281-1288.

19 Darrah R, McKone E, O'Connor C, Rodgers C, Genatossio A, McNamara S, et al: EDNRA variants associate with smooth muscle mRNA levels, cell proliferation rates, and cystic fibrosis pulmonary disease severity. Physiol Genomics 2010;41:71-77.

20 Hillian AD, Londono D, Dunn JM, Goddard KAB, Pace RG, Knowles MR, et al: Modulation of cystic fibrosis lung disease by variants in interleukin-8. Genes Immun 2008;9:501508 .

21 Hartl D, Latzin P, Hordijk P, Marcos V, Rudolph C, Woischnik M, et al: Cleavage of CXCR1 on neutrophils disables bacterial killing in cystic fibrosis lung disease. Nat Med 2007;13:1423-1430.

-22 Mayer-Hamblett N, Aitken ML, Accurso FJ, Kronmal RA, Konstan MW, Burns JL, et al: Association between pulmonary function and sputum biomarkers in cystic fibrosis. Am J Respir Crit Care Med 2007;175:822-828.

23 Sagel SD: Noninvasive biomarkers of airway inflammation in cystic fibrosis. Curr Opin Pulm Med 2003;9:516-521.

24 Cantin AM, Hartl D, Konstan MW, Chmiel JF: Inflammation in cystic fibrosis lung disease: pathogenesis and therapy. J Cyst Fibros 2015;14:419-430.

25 Griese M, Kappler M, Gaggar A, Hartl D: Inhibition of airway proteases in cystic fibrosis lung disease. Eur Respir J 2008;32:783-795. 
26 Moss RB, Mistry SJ, Konstan MW, Pilewski JM, Kerem E, Tal-Singer R, et al: Safety and early treatment effects of the CXCR2 antagonist SB-656933 in patients with cystic fibrosis. J Cyst Fibros 2013;12:241-248.

27 Tang AC, Turvey SE, Alves MP, Regamey N, Tümmler B, Hartl D: Current concepts: hostpathogen interactions in cystic fibrosis airways disease. Eur Respir Rev 2014;23:320332.

-28 Kruger P, Saffarzadeh M, Weber ANR, Rieber N, Radsak M, von Bernuth H, et al: Neutrophils: between host defence, immune modulation, and tissue injury. PLoS Pathog 2015; 11:1-22.

-29 Marcos V, Zhou-Suckow Z, Ønder Yildirim A, Bohla A, Hector A, Vitkov L, et al: Free DNA in cystic fibrosis airway fluids correlates with airflow obstruction. Mediators Inflamm 2015;2015:408935.

- 30 Fuchs HJ, Borowitz DS, Christiansen DH, Morris EM, Nash ML, Ramsey BW, et al: Effect of aerosolized recombinant human dnase on exacerbations of respiratory symptoms and on pulmonary function in patients with cystic fibrosis. N Engl J Med 1994;331:637642.

- 31 Dwyer M, Shan Q, D’Ortona S, Maurer R, Mitchell R, Olesen H, et al: Cystic fibrosis sputum DNA has NETosis characteristics and neutrophil extracellular trap release is regulated by macrophage migration-inhibitory factor. J Innate Immun 2014;6:765-779.

32 Cheng OZ, Palaniyar N: NET balancing: a problem in inflammatory lung diseases. Front Immunol 2013;4:1-13.

- 33 Branzk N, Papayannopoulos V: Molecular mechanisms regulating NETosis in infection and disease. Semin Immunopathol 2013;35: 513-530.

-34 Janeway CA: Approaching the asymptote? Evolution and revolution in immunology. Cold Spring Harb Symp Quant Biol 1989;54: $1-13$.

35 Lynch S V, Bruce KD: The cystic fibrosis airway microbiome. Cold Spring Harb Perspect Med 2013;3:a009738.

-36 Surette MG: The cystic fibrosis lung microbiome. Ann Am Thorac Soc 2014;11:61-65.

-37 Mahenthiralingam E: Emerging cystic fibrosis pathogens and the microbiome. Paediatr Respir Rev 2014;15:13-15.

- 38 Kawai T, Akira S: Toll-like receptors and their crosstalk with other innate receptors in infection and immunity. Immunity 2011;34:637650.

-39 De Bentzmann S, Roger P, Dupuit F, BajoletLaudtnat O, Fuchey C, Plotkowski MC, et al: Asialo GM1 is a receptor for Pseudomonas aeruginosa adherence to regenerating respiratory epithelial cells. Infect Immun 1996;64: $1582-1588$

-40 Sutterwala FS, Mijares L a, Li L, Ogura Y, Kazmierczak BI, Flavell R a: Immune recognition of Pseudomonas aeruginosa mediated by the IPAF/NLRC4 inflammasome. J Exp Med 2007;204:3235-3245.
41 McIsaac SM, Stadnyk AW, Lin T-J: Toll-like receptors in the host defense against Pseudomonas aeruginosa respiratory infection and cystic fibrosis. J Leukoc Biol 2012;92:977-985.

42 Epelman S, Stack D, Bell C, Wong E, Neely GG, Krutzik S, et al: Different domains of Pseudomonas aeruginosa exoenzyme S activate distinct TLRs. J Immunol 2004;173: 2031-2040.

43 Greene CM, Carroll TP, Smith SGJ, Taggart CC, Devaney J, Griffin S, et al: TLR-induced inflammation in cystic fibrosis and non-cystic fibrosis airway epithelial cells. J Immunol 2005;174:1638-1646.

-44 Travassos LH, Girardin SE, Philpott DJ, Blanot D, Nahori M-A, Werts C, et al: Toll-like receptor 2-dependent bacterial sensing does not occur via peptidoglycan recognition. EMBO Rep 2004;5:1000-1006.

-45 Flo TH, Ryan L, Latz E, Takeuchi O, Monks BG, Lien E, et al: Involvement of Toll-like receptor (TLR) 2 and TLR4 in cell activation by mannuronic acid polymers. J Biol Chem 2002;277:35489-35495.

46 Lagoumintzis G, Xaplanteri P, Dimitracopoulos G, Paliogianni F: TNF-alpha induction by Pseudomonas aeruginosa lipopolysaccharide or slime-glycolipoprotein in human monocytes is regulated at the level of mitogen-activated protein kinase activity: a distinct role of Toll-like receptor 2 and 4 . Scand J Immunol 2008;67:193-203.

-47 Husebye H, Halaas $\emptyset$, Stenmark H, Tunheim $G$, Sandanger $\varnothing$, Bogen B, et al: Endocytic pathways regulate Toll-like receptor 4 signaling and link innate and adaptive immunity. EMBO J 2006;25:683-692.

48 Miyake K, Ogata H, Nagai Y, Akashi S, Kimoto $\mathrm{M}$ : Innate recognition of lipopolysaccharide by Toll-like receptor $4 / \mathrm{MD}-2$ and RP105/MD-1. Immunology 2000;6:3-5.

49 Hajjar AM, Ernst RK, Tsai JH, Wilson CB, Miller SI: Human Toll-like receptor 4 recognizes host-specific LPS modifications. Nat Immunol 2002;3:354-359.

50 Ernst RK, Yi EC, Guo L, Lim KB, Burns JL, Hackett M, et al: Specific lipopolysaccharide found in cystic fibrosis airway Pseudomonas aeruginosa. Science 1999;286:1561-1565.

51 Ernst RK, Hajjar AM, Tsai JH, Moskowitz SM, Wilson CB, Miller SI: Pseudomonas aeruginosa lipid A diversity and its recognition by Toll-like receptor 4. J Endotoxin Res 2003;9: 395-400.

52 Di Lorenzo F, Kubik Ł, Oblak A, Lorè NI, Cigana C, Lanzetta R, et al: Activation of human Toll-like receptor 4 (TLR4) myeloid differentiation factor 2 (MD-2) by hypoacylated lipopolysaccharide from a clinical isolate of Burkholderia cenocepacia. J Biol Chem 2015; 290:21305-21319.

53 Hayashi F, Smith KD, Ozinsky A, Hawn TR, Yi EC, Goodlett DR, et al: The innate immune response to bacterial flagellin is mediated by Toll-like receptor 5. Nature 2001;410:1099103.
54 Amiel E, Lovewell RR, O’Toole GA, Hogan DA, Berwin B: Pseudomonas aeruginosa evasion of phagocytosis is mediated by loss of swimming motility and is independent of flagellum expression. Infect Immun 2010;78: 2937-2945.

55 Balloy V, Verma A, Kuravi S, Si-Tahar M, Chignard M, Ramphal R: The role of flagellin versus motility in acute lung disease caused by Pseudomonas aeruginosa. J Infect Dis 2007; 196:289-296.

56 Descamps D, Le Gars M, Balloy V, Barbier D, Maschalidi S, Tohme M, et al: Toll-like receptor 5 (TLR5), IL-1beta secretion, and asparagine endopeptidase are critical factors for alveolar macrophage phagocytosis and bacterial killing. Proc Natl Acad Sci USA 2012;109: 1619-1624.

57 Barton GM, Kagan JC, Medzhitov R: Intracellular localization of Toll-like receptor 9 prevents recognition of self DNA but facilitates access to viral DNA. Nat Immunol 2006;7: 49-56.

58 Hemmi H, Takeuchi O, Kawai T, Kaisho T, Sato S, Sanjo H, et al: A Toll-like receptor recognizes bacterial DNA. Nature 2000;408: 740-745.

59 Duggan JM, You D, Cleaver JO, Larson DT, Garza RJ, Guzman Pruneda FA, et al: Synergistic interactions of TLR2/6 and TLR9 induce a high level of resistance to lung infection in mice. J Immunol 2011;186:5916-5926.

60 Benmohamed F, Medina M, Wu YZ, Maschalidi S, Jouvion G, Guillemot L, et al: Tolllike receptor 9 deficiency protects mice against Pseudomonas aeruginosa lung infection. PLoS One 2014;9:e90466.

61 Fritz JH, Ferrero RL, Philpott DJ, Girardin SE: Nod-like proteins in immunity, inflammation and disease [Internet]. Nat Immunol 2006;7:1250-1257.

62 Inohara $\mathrm{N}$, Chamaillard M, McDonald C, $\mathrm{Nu}$ ñez G: NOD-LRR proteins: role in host-microbial interactions and inflammatory disease. Annu Rev Biochem 2005;74:355-383.

63 Mariathasan S, Monack DM: Inflammasome adaptors and sensors: intracellular regulators of infection and inflammation. Nat Rev Immunol 2007;7:31-40.

64 Miao EA, Warren SE: Innate immune detection of bacterial virulence factors via the NLRC4 inflammasome. J Clin Immunol 2010;30:502-506.

65 Tenthorey JL, Kofoed EM, Daugherty MD, Malik H, Vance RE: Molecular basis for specific recognition of bacterial ligands by NAIP/ NLRC4 inflammasomes. Mol Cell 2014;54: $17-29$.

66 Faure E, Mear JB, Faure K, Normand S, Couturier-Maillard A, Grandjean T, et al: Pseudomonas aeruginosa type-3 secretion system dampens host defense by exploiting the NLRC4-coupled inflammasome. Am J Respir Crit Care Med 2014;189:799-811.

67 Vance RE: The NAIP/NLRC4 inflammasomes. Curr Opin Immunol 2015;32:84-89. 
-68 Leissinger M, Kulkarni R, Zemans RL, Downeyn GP, Jeyaseelan S: Investigating the role of nucleotide-binding oligomerization domain-like receptors in bacterial lung infection. Am J Respir Crit Care Med 2014;189: 1461-1468.

-69 Lage SL, Longo C, Branco LM, da Costa TB, Buzzo C de L, Bortoluci KR: Emerging concepts about NAIP/NLRC4 inflammasomes. Front Immunol 2014;5:1-10.

70 Zhao Y, Shao F: The NAIP-NLRC4 inflammasome in innate immune detection of bacterial flagellin and type III secretion apparatus. Immunol Rev 2015;265:85-102.

-71 Li W, Yang J, Zhang E, Zhong M, Xiao Y, Yu J, et al: Activation of NLRC4 downregulates TLR5-mediated antibody immune responses against flagellin. Cell Mol Immunol 2015, Epub ahead of print.

-72 Franchi L, Amer A, Body-Malapel M, Kanneganti TD, Ozoren N, Jagirdar R, et al: Cytosolic flagellin requires Ipaf for activation of caspase- 1 and interleukin 1beta in salmonella-infected macrophages. Nat Immunol 2006; 7:576-582.

73 Mariathasan S, Newton K, Monack DM, Vucic D, French DM, Lee WP, et al: Differential activation of the inflammasome by caspase- 1 adaptors ASC and Ipaf. Nature 2004; 430:213-218.

-74 Zamboni DS, Kobayashi KS, Kohlsdorf T, Ogura Y, Long EM, Vance RE, et al: The Bircle cytosolic pattern-recognition receptor contributes to the detection and control of $L e$ gionella pneumophila infection. Nat Immunol 2006;7:318-325.

-75 Suzuki T, Franchi L, Toma C, Ashida H, Ogawa $\mathrm{M}$, Yoshikawa Y, et al: Differential regulation of caspase- 1 activation, pyroptosis, and autophagy via Ipaf and ASC in Shigella-infected macrophages. PLoS Pathog 2007;3: 1082-1091.

-76 Grassmé H, Carpinteiro A, Edwards MJ, Gulbins E, Becker KA: Regulation of the inflammasome by ceramide in cystic fibrosis lungs. Cell Physiol Biochem 2014;34:45-55.

-77 Juliana C, Fernandes-Alnemri T, Kang S, Farias A, Qin F, Alnemri ES: Non-transcriptional priming and deubiquitination regulate NLRP3 inflammasome activation. J Biol Chem 2012;287:36617-36622.

78 Rimessi A, Bezzerri V, Patergnani S, Marchi S, Cabrini G, Pinton P: Mitochondrial $\mathrm{Ca}(2+)$-dependent NLRP3 activation exacerbates the Pseudomonas aeruginosa-driven inflammatory response in cystic fibrosis. Nat Commun 2015;6:6201.

79 Lee S, Suh G, Ryter SW, Choi AMK: Regulation and function of the NLRP3 inflammasome in lung disease. Am J Respir Cell Mol Biol 2015;54:1-28.

80 Balloy V, Chignard M: The innate immune response to Aspergillus fumigatus. Microbes Infect 2009;11:919-927.

-81 Morton CO, Bouzani M, Loeffler J, Rogers TR: Direct interaction studies between Aspergillus fumigatus and human immune cells; what have we learned about pathogenicity and host immunity? Front Microbiol 2012;3:1-7.

82 Alekseeva L, Huet D, Féménia F, Mouyna I, Abdelouahab M, Cagna A, et al: Inducible expression of beta defensins by human respiratory epithelial cells exposed to Aspergillus fumigatus organisms. BMC Microbiol 2009;9: 33.

83 Hartl D: Immunological mechanisms behind the cystic fibrosis-ABPA link. Med Mycol 2009;47(suppl 1):S183-91.

84 Chotirmall SH, Al-Alawi M, Mirkovic B, Lavelle G, Logan PM, Greene CM, et al: Aspergillus-associated airway disease, inflammation, and the innate immune response. Biomed Res Int 2013;2013:723129.

85 Margalit A, Kavanagh K: The innate immune response to Aspergillus fumigatus at the alveolar surface. FEMS Microbiol Rev 2015;39: 670-687.

86 Delhaes L, Monchy S, Fréalle E, Hubans C, Salleron J, Leroy S, et al: The airway microbiota in cystic fibrosis: a complex fungal and bacterial community-implications for therapeutic management. PLoS One 2012; 7:e36313.

87 Middleton PG, Chen SC, Meyer W: Fungal infections and treatment in cystic fibrosis. Curr Opin Pulm Med 2013;19:670-675.

88 Chotirmall SH, McElvaney NG: Fungi in the cystic fibrosis lung: bystanders or pathogens? Int J Biochem Cell Biol 2014;52:161-173.

89 Pihet M, Carrere J, Cimon B, Chabasse D, Delhaes L, Symoens F, et al: Occurrence and relevance of filamentous fungi in respiratory secretions of patients with cystic fibrosis - a review. Med Mycol 2009;47:387-397.

90 Sudfeld CR, Dasenbrook EC, Merz WG, Carroll KC, Boyle MP: Prevalence and risk factors for recovery of filamentous fungi in individuals with cystic fibrosis. J Cyst Fibros 2010;9: 110-116.

91 Hartl D, Latzin P, Zissel G, Krane M, KraussEtschmann S, Griese M: Chemokines indicate allergic bronchopulmonary aspergillosis in patients with cystic fibrosis. Am J Respir Crit Care Med 2006;173:1370-1376.

92 Brown GD: Innate antifungal immunity: the key role of phagocytes. Annu Rev Immunol 2011;29:1-21.

93 Plato A, Hardison SE, Brown GD: Pattern recognition receptors in antifungal immunity. Semin Immunopathol 2015;37:97-106.

94 DeHart DJ, Agwu DE, Julian NC, Washburn RG: Binding and germination of Aspergillus fumigatus conidia on cultured A549 pneumocytes. J Infect Dis 1997;175:146-150.

95 Roeder A, Kirschning CJ, Rupec RA, Schaller M, Weindl G, Korting HC: Toll-like receptors as key mediators in innate antifungal immunity. Med Mycol 2004;42:485-498.

96 Bellocchio S, Montagnoli C, Bozza S, Gaziano R, Rossi G, Mambula SS, et al: The contribution of the Toll-like/IL-1 receptor superfamily to innate and adaptive immunity to fungal pathogens in vivo. J Immunol 2004; 172: 3059-3069.
-97 Sun W-K, Lu X, Li X, Sun Q-Y, Su X, Song $\mathrm{Y}$, et al: Dectin-1 is inducible and plays a crucial role in Aspergillus-induced innate immune responses in human bronchial epithelial cells. Eur J Clin Microbiol Infect Dis 2012;31:2755-2764.

98 Mambula SS, Sau K, Henneke P, Golenbock DT, Levitz SM: Toll-like receptor (TLR) signaling in response to Aspergillus fumigatus. J Biol Chem 2002;277:39320-39326.

-99 Blease K, Kunkel SL, Hogaboam CM: IL-18 modulates chronic fungal asthma in a murine model; putative involvement of Tolllike receptor-2. Inflamm Res 2001;50:552560.

100 Braedel S, Radsak M, Einsele H, Latgé J-P, Michan A, Loeffler J, et al: Aspergillus fumigatus antigens activate innate immune cells via Toll-like receptors 2 and 4. Br J Haematol 2004;125:392-399.

101 Meier A, Kirschning CJ, Nikolaus T, Wagner H, Heesemann J, Ebel F: Toll-like receptor (TLR) 2 and TLR4 are essential for Aspergillus-induced activation of murine macrophages. Cell Microbiol 2003;5:561570.

102 Steele C, Rapaka RR, Metz A, Pop SM, Williams DL, Gordon S, et al: The beta-glucan receptor dectin-1 recognizes specific morphologies of Aspergillus fumigatus. PLoS Pathog 2005; 1:0323-0334.

103 Hohl TM, Van Epps HL, Rivera A, Morgan LA, Chen PL, Feldmesser M, et al: Aspergillus fumigatus triggers inflammatory responses by stage-specific beta-glucan display. PLoS Pathog 2005;1:0232-0240.

104 Hamon Y, Jaillon S, Person C, Giniès J-L, Garo E, Bottazzi B, et al: Proteolytic cleavage of the long pentraxin PTX3 in the airways of cystic fibrosis patients. Innate Immun 2013; 19:611-622.

105 Bidula S, Sexton DW, Yates M, Abdolrasouli A, Shah A, Wallis $\mathrm{R}$, et al: $\mathrm{H}$-ficolin binds Aspergillus fumigatus leading to activation of the lectin complement pathway and modulation of lung epithelial immune responses. Immunology 2015;146:281291.

106 Hiemstra PS, Mccray Jr PB, Bals R: The innate immune function of airway epithelial cells in inflammatory lung disease. Eur Respir J 2015;1-13.

107 Holtzman MJ, Byers DE, Alexander-Brett J, Wang X: The role of airway epithelial cells and innate immune cells in chronic respiratory disease. Nat Rev Immunol 2014;14: 686-698.

108 Pier GB, Grout M, Zaidi T, Meluleni G, Mueschenborn SS, Banting G, et al: Salmonella typhi uses CFTR to enter intestinal epithelial cells. Nature 1998;393:79-82.

109 Pier GB, Grout M, Zaidi TS: Cystic fibrosis transmembrane conductance regulator is an epithelial cell receptor for clearance of Pseudomonas aeruginosa from the lung. Proc Natl Acad Sci USA 1997;94:1208812093. 
110 Bajmoczi M, Gadjeva M, Alper SL, Pier GB, Golan DE: Cystic fibrosis transmembrane conductance regulator and caveolin-1 regulate epithelial cell internalization of Pseudomonas aeruginosa 2009;263-277.

-111 Chaudhary N, Datta K, Askin FB, Staab JF, Marr KA: Cystic fibrosis transmembrane conductance regulator regulates epithelial cell response to Aspergillus and resultant pulmonary inflammation. Am J Respir Crit Care Med 2012;185:301-310.

-112 Mayer AK, Muehmer M, Mages J, Gueinzius $\mathrm{K}$, Hess C, Heeg K, et al: Differential recognition of TLR-dependent microbial ligands in human bronchial epithelial cells. J Immunol 2007; 178:3134-3142.

113 Blohmke CJ, Park J, Hirschfeld AF, Victor RE, Schneiderman J, Stefanowicz D, et al: TLR5 as an anti-inflammatory target and modifier gene in cystic fibrosis. J Immunol 2010;185:7731-7738.

-114 Raoust E, Balloy V, Garcia-Verdugo I, Touqui L, Ramphal R, Chignard M: Pseudomonas aeruginosa LPS or flagellin are sufficient to activate TLR-dependent signaling in murine alveolar macrophages and airway epithelial cells. PLoS One 2009;4:e7259.

-115 John G, Yildirim AÖ, Rubin BK, Gruenert DC, Henke MO: TLR-4-mediated innate immunity is reduced in cystic fibrosis airway cells. Am J Respir Cell Mol Biol 2010; 42:424-431.

116 Bruscia EM, Zhang P-X, Satoh A, Caputo C, Medzhitov R, Shenoy A, et al: Abnormal trafficking and degradation of TLR4 underlie the elevated inflammatory response in cystic fibrosis. J Immunol 2011;186:69906998.

\17 Kelly C, Canning P, Buchanan PJ, Williams MT, Brown V, Gruenert DC, et al: Toll-like receptor 4 is not targeted to the lysosome in cystic fibrosis airway epithelial cells. Am J Physiol Lung Cell Mol Physiol 2013; 304:L371-L382.

-118 Jia HP, Kline JN, Penisten A, Apicella M a, Gioannini TL, Weiss J, et al: Endotoxin responsiveness of human airway epithelia is limited by low expression of MD-2. Am J Physiol Lung Cell Mol Physiol 2004; 287:L428-L437.

119 Feuillet V, Medjane S, Mondor I, Demaria O, Pagni PP, Galán JE, et al: Involvement of Toll-like receptor 5 in the recognition of flagellated bacteria. Proc Natl Acad Sci USA 2006;103:12487-12492.

-120 Zhang Z, Louboutin J, Weiner DJ, Goldberg JB, Wilson JM: Human Airway epithelial cells sense Pseudomonas aeruginosa infection via recognition of flagellin by Toll-like receptor 5. Infect Immun 2005;73:71517160 .

121 Tseng J, Do J, Widdicombe JH, Machen TE: Innate immune responses of human tracheal epithelium to Pseudomonas aeruginosa flagellin, TNF-alpha, and IL-1beta. Am J Physiol Cell Physiol 2006;290:678-690.

122 Kato K, Lillehoj EP, Park YS, Umehara T, Hoffman NE, Madesh M, et al: Membranetethered MUC1 mucin is phosphorylated by epidermal growth factor receptor in airway epithelial cells and associates with TLR5 to inhibit recruitment of MyD88. J Immunol 2012;188:2014-2022.

123 Adamo R, Sokol S, Soong G, Gomez MI, Prince A: Pseudomonas aeruginosa flagella activate airway epithelial cells through asialoGM1 and Toll-like receptor 2 as well as Toll-like receptor 5. Am J Respir Cell Mol Biol 2004;30:627-634.

124 Muir A, Soong G, Sokol S, Reddy B, Gomez MI, Van Heeckeren A, et al: Toll-like receptors in normal and cystic fibrosis airway epithelial cells. Am J Respir Cell Mol Biol 2004; 30:777-783.

- 25 Hybiske K, Ichikawa JK, Huang V, Lory SJ, Machen TE: Cystic fibrosis airway epithelial cell polarity and bacterial flagellin determine host response to Pseudomonas aeruginosa. Cell Microbiol 2004;6:49-63.

126 Mizunoe S, Shuto T, Suzuki S, Matsumoto C, Watanabe K, Ueno-Shuto K, et al: Synergism between interleukin (IL)-17 and Tolllike receptor 2 and 4 signals to induce IL-8 expression in cystic fibrosis airway epithelial cells. J Pharmacol Sci 2012;118:512-520.

127 Kempaiah P, Davidson LB, Perkins DJ, Byrd TF: Cystic fibrosis CFBE41o- cells contain TLR1 SNP I602S and fail to respond to $M y$ cobacterium abscessus. J Cyst Fibros 2013; 12:773-779.

128 Haerynck F, Mahachie John JM, Van Steen K, Schelstraete P, Van daele S, Loeys B, et al: Genetic variations in Toll-like receptor pathway and lung function decline in cystic fibrosis patients. Hum Immunol 2013;74: 1649-1655.

129 Chekabab SM, Silverman RJ, Lafayette SL, Luo Y, Rousseau S, Nguyen D, et al: Staphylococcus aureus inhibits IL-8 responses induced by Pseudomonas aeruginosa in airway epithelial cells. PLoS One 2015;10:1-19.

130 Koller B, Kappler M, Latzin P, Gaggar A, Schreiner M, Takyar S, et al: TLR expression on neutrophils at the pulmonary site of infection: TLR1/TLR2-mediated up-regulation of TLR5 expression in cystic fibrosis lung disease. J Immunol 2008;181:27532763.

131 Koller B, Bals R, Roos D, Korting HC, Griese $M$, Hartl D: Innate immune receptors on neutrophils and their role in chronic lung disease. Eur J Clin Invest 2009;39:535-547.

132 Petit-Bertron AF, Tabary O, Corvol H, Jacquot J, Clément A, Cavaillon JM, et al: Circulating and airway neutrophils in cystic fibrosis display different TLR expression and responsiveness to interleukin-10. Cytokine 2008;41:54-60.
133 Gaggar A, Rowe SM, Matthew H, Blalock JE: Proline-glycine-proline (PGP) and high mobility group box protein-1 (HMGB1): potential mediators of cystic fibrosis airway inflammation. Open Respir Med J 2010;4: 32-38.

134 Makam M, Diaz D, Laval J, Gernez Y, Conrad CK, Dunn CE, et al: Activation of critical, host-induced, metabolic and stress pathways marks neutrophil entry into cystic fibrosis lungs. Proc Natl Acad Sci USA 2009; 106:5779-5783.

135 Nichols DP, Konstan MW, Chmiel JF: Antiinflammatory therapies for cystic fibrosisrelated lung disease. Clin Rev Allergy Immunol 2008;35:135-153.

136 Konstan MW, Byard PJ, Hoppel CL, Davis PB: Effect of high-dose ibuprofen in patients with cystic fibrosis. N Engl J Med 1995;332: 848-854.

137 Konstan MW, Schluchter MD, Xue W, Davis $\mathrm{PB}$ : Clinical use of ibuprofen is associated with slower FEV1 decline in children with cystic fibrosis. Am J Respir Crit Care Med 2007;176:1084-1089.

138 Konstan MW: Ibuprofen therapy for cystic fibrosis lung disease: revisited. Curr Opin Pulm Med 2008;14:567-573.

139 Chmiel JF, Konstan MW, Accurso FJ, Lymp J, Mayer-Hamblett N, VanDevanter DR, et al: Use of ibuprofen to assess inflammatory biomarkers in induced sputum: implications for clinical trials in cystic fibrosis. J Cyst Fibros 2015;14:720-726.

140 Conrad C, Lymp J, Thompson V, Dunn C, Davies Z, Chatfield B, et al: Long-term treatment with oral $\mathrm{N}$-acetylcysteine affects lung function but not sputum inflammation in cystic fibrosis subjects. A phase II randomized placebo-controlled trial. J Cyst Fibros 2015;14:219-227.

141 McElvaney NG: Alpha-1 antitrypsin therapy in cystic fibrosis and the lung disease associated with alpha-1 antitrypsin deficiency. Ann Am Thorac Soc 2016;13:191196.

142 Ratjen F, Saiman L, Mayer-Hamblett N, Lands LC, Kloster M, Thompson V, et al: Effect of azithromycin on systemic markers of inflammation in patients with cystic fibrosis uninfected with Pseudomonas aeruginosa. Chest 2012;142:1259-1266.

143 Taylor-Cousar JL, Wiley C, Felton LA, St. Clair C, Jones M, Curran-Everett D, et al: Pharmacokinetics and tolerability of oral sildenafil in adults with cystic fibrosis lung disease. J Cyst Fibros 2015;14:228-236.

144 Levy BD, Serhan CN: Resolution of acute inflammation in the lung. Annu Rev Physiol 2014;76:467-492.

145 Di Marzo V, Bifulco M, De Petrocellis L: The endocannabinoid system and its therapeutic exploitation. Nat Rev Drug Discov 2004;3:771-784. 